\title{
Habilidades en la alta gestión y política universitarias
}

\author{
Skills in senior management and university policy
}

\section{David Vallespín Pérez}

Catedrático de Derecho Procesal

Departamento de Derecho Administrativo, Derecho Procesal y Derecho Financiero y Tributario.

Facultad de Derecho, Universidad de Barcelona.

E-mail: dvallespin@ub.edu

\begin{abstract}
Resumen: El presente artículo centra su atención en el examen de aquel conjunto de habilidades que deberían acompañar, en todo momento, a quienes desempeñan en la Universidad Pública labores de alta gestión y responsabilidad. A tal efecto, metodológicamente, se parte del análisis del liderazgo de la máxima autoridad académica de la Universidad con especial atención, de una parte, al papel que le debe corresponde al rector o rectora en la gestión de la toma de decisiones, la planificación e implementación de la dinámica de trabajo de su equipo de dirección y la gestión de conflictos entre los diferentes estamentos universitarios; y de otra, a lo que deben ser, desde su propio ejemplo, sus habilidades de negociación y comunicación. Utilizando un procedimiento interdisciplinar y transversal, en el que confluyen Educación, Psicología y Derecho, se termina por concluir, previo análisis comparado de los diferentes estilos de liderazgo (commanding, visionary, affiliative, democratic, pacesetting y coaching), que, dependiendo de las circunstancias de cada momento y en función de los problemas a resolver, todos y cada uno de ellos pueden resultar útiles en manos de un rector o rectora que, siendo líder, sepa ejercer como tal, tenga la habilidad de hacerse las preguntas oportunas en cada caso, escuchando activamente a toda la comunidad universitaria, y que proyecte su dedicación y voluntad de servicio en el interés común de la institución universitaria que dirige.

Palabras clave: Política universitaria, Liderazgo, Gestión Universitaria, Toma de decisiones, Rectorado.
\end{abstract}


Abstract: This article focuses on the review of set of skills that should accompany, at all times, those who perform the Public University tasks of senior management and responsibility. In respect thereof, this article analyzes, methodologically, the leadership of the highest academic authority of the University with special attention, on the one hand, to the role that corresponds to the rector of the university in the management of decision making, planning and implementation of the dynamics of work of management team, and conflict management between the different university levels; and on the other hand, to what they should be, from their own example, their negotiation and communication skills. By using an interdisciplinary and transversal procedure, in which Education, Psychology and Law converge, it's concluded, after a comparative analysis of the different leadership styles (commanding, visionary, affiliative, democratic, pacesetting and coaching) that, depending on circumstances of each moment and the issues to be address, all and each of them can be useful in the hands of a rector of the university who, being a leader, knows how to exercise as such, has the ability to ask the appropriate questions in each case, actively listening to the entire university community, and who projects his dedication and willingness to serve in the common interest of the university institution that manages.

Keywords: University policy, Leadership, University management, Decision making, University rectorate.

SUMARIO: I.- Introducción. II.- Gestión de la toma de decisiones (escucha activa). III.- Las personas. IV.- Conocimiento actualizado de la realidad. V.- Equilibrio entre decidir y confiar en el equipo. VI.Gestión de conflictos. VII.- Saber comunicar. VIII.- Innovación equilibrada. IX.- El valor de la intuición. X.- Habilidades de negociación. XI.- Entusiasmo y espíritu de superación. XII.- Predicar con el ejemplo. XIII.- Los diferentes estilos de liderazgo y su aplicación en el ámbito de la Universidad Pública. XIV.Notas conclusivas sobre las habilidades de la alta gestión y la política universitaria. Bibliografía referenciada. 


\section{I.- Introducción}

En el ámbito de la alta gestión y política universitaria conseguir buenos resultados en los rankings, en relación a las actividades de docencia, investigación y transferencia e innovación, es indispensable, pero no suficiente. Tanto o más importante es saber dirigir personas, innovar, comunicar, generar confianza y arremangarse, como el que más, para luchar en defensa de la institución que se dirige, así como de los derechos e intereses legítimos de los diferentes estamentos universitarios: personal docente e investigador, personal de administración y servicios, y las y los estudiantes que configuran, en verdad, la auténtica razón de ser de toda Universidad Pública (MIRÓN, 2008, 5).

Un buen líder, también en el ámbito universitario, es aquel que sabe guiar, pues conoce el camino, sigue el camino y muestra el camino (MAXWELL, 2014, 31). El liderazgo del rector o rectora es clave, tanto a nivel individual como grupal, para que la Universidad funcione. Dicho liderazgo debe sustentarse, como indican Brunner (2011, 140-141) y Pulido (2016, 286), en la combinación ponderada entre motivación y resultados. De ahí la importancia de apostar, en el momento actual, por un modelo colegial de Universidad con participación de partes interesadas (VALLESPÍN, 2019, 1$3)$.

El éxito de una institución universitaria, sin perjuicio de diferentes factores exógenos como, por ejemplo, el contar con presupuestos estables y suficientes, así como con una apuesta política decidida por la potenciación de la sociedad del conocimiento (PONS, 2013, 1-20), también depende, en buena medida, de las habilidades que la máxima autoridad académica universitaria tenga en orden a ejercer, equilibrando la toma de decisiones con la prudencia, su responsabilidad compartida, desde luego, con los integrantes de su equipo, los equipos de dirección de las diferentes Facultades, Departamentos y Secciones Departamentales y, por supuesto, con todos los miembros de la comunidad universitaria (MARIANOV y VON, 2006, 133-135).

Habilidades entre las cuales, como remarcan Murillo y Salas (2011, 5), también deben tener cabida tanto un comportamiento guiado por la ética en el ejercicio del cargo, como su formación en materia ejecutiva y económica (bien del propio rector, que no estaría de más o, en todo caso, de su equipo económico). Pero en el bien entendido que las habilidades técnicas del ejecutivo, como aquellas relativas a la lectura de un balance general, la estimación del valor descontado o la capacidad de endeudamiento, aun 
siendo importantes, no dejan de ser trivialidades comparadas con el entendimiento de la naturaleza fundamental que es propia de la Universidad (ROSOVSKY, 2010, 240).

Algunas condiciones y habilidades de liderazgo son innatas a algunas personas, pero ello no excluye que éstas puedan ejercitarse e, incluso, en algunos casos, que lleguen a adquirirse con trabajo. Estas habilidades, sin ánimo exhaustivo, bien podrían resumirse en doce: la gestión de la toma de decisiones, la ponderación de las personas, el saber motivar, el aprovechamiento del talento actualizado, el equilibrio entre decidir y confiar en su equipo, la gestión de hipotéticos conflictos, el saber comunicar, la innovación, la toma en consideración, en la dosis adecuada, de la intuición, la aplicación de técnicas de negociación dirigidas a conseguir, con manejo de la empatía, el máximo consenso posible en la toma de acuerdos; el entusiasmo y espíritu de superación y la capacidad de predicar con el ejemplo (SAN JUAN y BUENO 2017, 256-259).

Todas ellas giran alrededor de un triángulo básico: la definición del foco, pues no hay nadie más desmotivador que aquél o aquélla que no sabe hacia dónde va y, en consecuencia, no sabe conducir a quiénes de él o ella dependen; la necesidad de desarrollar el talento de los integrantes de su equipo y colaboradores, haciéndoles partícipes de un proyecto bien definido y estructurado (VALLESPÍN, 2013, 1-8); y saber hacer sentir tanto a sus compañeros de viaje en la alta gestión y dirección de la Universidad, así como a los diferentes integrantes de la comunidad universitaria, que todas y todos son importantes, valorando las diferencias y conociendo lo que cada persona es capaz de aportar a la institución desde la potencialidad de sus fortalezas, experiencias y maneras de ser y actuar (CABEZAS, AIGER y PALACÍN, 2017, 141158).

Aprovechando la que ha sido mi experiencia en la alta gestión de gobierno de la Universitat de Barcelona expondré, a continuación, fruto de lo vivido y espero que aprendido, algunas reflexiones acerca de cómo dichas habilidades debieran implementarse en la práctica en una institución universitaria pública. Todo ello teniendo bien presente, de una parte, que todo rector o rectora debiera empezar por disfrutar de su responsabilidad, ser siempre realista, pero positivo, y coherente con lo que dice y hace; y, de otra, que nadie ha sido, es, o será perfecto, ya que quien así lo crea, alejándose de la humildad siempre necesaria, más que alguien a quien seguir, acabará configurándose como una triste caricatura de sí mismo. 


\section{II.- Gestión de la toma de decisiones (escucha activa)}

La máxima autoridad universitaria en su quehacer diario, como es fácil pensar, viene obligada a tomar decisiones. La gestión de esta habilidad no es tarea fácil y, todavía menos, en una Universidad, como la de Barcelona, de gran dimensión, no solo institucional, sino también dada por el volumen heterogéneo de personas que la integran (NOVAK, TERRENCE y MACTAGGART, 2008, 6).

Para tomar cualquier decisión es presupuesto indispensable estar bien informado, así como ser capaz de analizar el contexto, tanto nacional como internacional, con una perspectiva no solo de presente, sino también de futuro (ANDRÉS, 2017, 13). Conocer la situación que obliga a la toma de una decisión, escuchar a quienes te rodean, saber interpretarla en aras a calibrar sus repercusiones, ser capaz de idear un plan de corrección de la decisión tomada si las circunstancias cambian sorpresivamente, o tener la capacidad de reconocer hipotéticos errores propios de la condición humana, que bien pudieran conducir a ciertos ajustes y/o correcciones, constituyen una buena estrategia para acertar, cargarse de razones en la toma de dicha decisión y estar en condiciones, con la conciencia tranquila, de dar explicaciones motivadas y rendir cuentas a los miembros de la comunidad universitaria.

Se plantea así el reto de la "escucha activa" que implica observar y preguntar, flexibilidad, confianza, apertura y firmeza. Tal como remarcan Pulido, Artiles y Aguiar $(2015,224)$ no es suficiente con saber qué necesidades tiene la comunidad universitaria, sino que es obligado escucharla de forma "activa", es decir, reuniendo y respetando todas sus opiniones y aportaciones con el objetivo último de tener mayores garantías de éxito en la toma de decisiones. El manejo de dicha información es la que permitirá al rector o rectora llegar a soluciones de consenso que, en ocasiones, no serán perfectas, pero si las mejores y únicas posibles en un momento y contexto concretos.

En un mundo como el actual, presidido por la globalización y los cambios constantes, no parece de recibo que algunos equipos rectorales, pensando en su tranquilidad y ahorrarse problemas, opten por la peor de las decisiones, esto es, por una opción inmovilista en la que no se toma decisión alguna o, de tomarse, solo persigue fines propagandísticos, vacíos de cualquier contenido práctico y operativo (NOVAK, TERRENCE y MACTAGGART, 2008, 8). Quien así actúa, mejor haría en apartarse y volver a su Facultad, bien a trabajar sobre algoritmos, nuevas fórmulas científicas, nuevos pensamientos o en la proyección de nuevos textos normativos. 


\section{III.- Las personas}

En línea con Di Napoli (2009, 6-7), los resultados, por excelentes que puedan ser, siempre deben conjugarse con la capacidad para gestionar y dirigir personas, tanto a nivel de cargos académicos como de administración; así como con el saber tratar, con empatía, a los diferentes colectivos que conforman la Universidad.

Saber colocar en su sitio a cada miembro del equipo rectoral, acertar en el mix del equipo o supervisar el anclaje del personal administrativo de soporte a los órganos de gobierno, son habilidades básicas para alcanzar, con buen clima de trabajo interno y la satisfacción laboral de los implicados, una gestión mucho más eficaz (MARTÍNEZ, 2012, 110-112). El rector o rectora debe ser capaz de marcar objetivos, dar sentido y poner en valor a quien está llamado a realizarlos, desarrollar y aprovechar el talento interno y hacer que cada persona se sienta útil e importante en el cumplimiento de sus funciones (RESTREPO y RESTREPO, 2012, 125).

El rector o rectora debiera desempeñar su cargo "dando ejemplo" de buen trato personal a los miembros de su propio equipo, así como a sus colaboradores en la gestión y organización administrativa. Y, por descontado, debiera practicar empatía y cualidad humana en el día a día del ejercicio de su responsabilidad, así como resultar cercano a cualquier miembro de la comunidad universitaria (GOLEMAN, 1996, 29). No parece un buen modelo a seguir el de aquel rector o rectora que, tras presentarse a las elecciones con un equipo integrado por una decena de vicerrectores y vicerrectoras, apenas un año más tarde, en contraposición a lo que fueron sus palabras en campaña relativas a la elección de un equipo cohesionado, termina por cesar a más de la mitad de esos vicerrectores o vicerrectoras en áreas tan básicas como docencia, estudiantes, profesorado, economía y comunicación. Tampoco parece un buen ejemplo el de un equipo rectoral que en menos de tres años de mandato, en un claro reflejo de su improvisación, se haya visto abocado a trabajar con tres gerentes distintos o a cambiar, sucesivamente, en más de una ocasión, de jefe de gabinete. Sin estabilidad parece difícil gobernar con un mínimo grado de seriedad.

\section{IV.- Conocimiento actualizado de la realidad}

El líder de un equipo rectoral debe ser coherente entre lo que le dice a sus miembros y, en paralelo, a los diferentes estamentos de la comunidad universitaria, así como claro en 
orden a la fijación compartida de metas y objetivos (RESTREPO y RESTREPO, 2012, 123-124).

Un rector o rectora que aprovecha los dos claustros ordinarios anuales para repetir frías cifras, de forma aburrida, así como para dar vueltas sobre lo que fue su programa electoral cuando, en verdad, no constan casi medidas de su implementación, más allá de "marear la perdiz" en una acción propia de quien no tiene nada ilusionante que explicar o proponer, termina por provocar un desinterés de la comunidad universitaria en relación a los temas que afectan y preocupan a la institución. Lo mismo puede decirse de aquella rectora o rector que en dichos claustros, lejos de explicar su actividad anual de gestión, opta por "entretener" a los claustrales con sucesivos programas de definición de metas de futuro, quizás bien intencionados y necesarios como "pieza de diagnóstico y de planificación”, pero de impredecible aplicación años más tarde de aquel en que finalice su propio mandato.

Cualquier ámbito de la alta gestión y política universitaria requiere no solo un completo conocimiento de la realidad de la institución y del contexto, acompañado de la consulta a los especialistas en cada materia cuando así sea conveniente, sino también una constante actualización de dicho conocimiento (DI NAPOLI, 2009, 8). Un rector o rectora que casi no habla con nadie, ni siquiera para darle los buenos días y que, por supuesto, se mantiene encerrado en su despacho (por mucho que se lo haya reformado nada más tomar posesión) sin contacto alguno con lo que acontece en las facultades o departamentos, esto es, con lo que preocupa, de verdad, a las personas involucradas en la institución que representa, tampoco parece una buena opción para dirigir una institución pública de educación superior.

Antes al contrario, el rector o rectora debiera preocuparse, en un ejercicio de "formación continuada" y reciclaje de su propio conocimiento, por saber, periódicamente, qué preocupa al personal de administración y servicios, al personal académico e investigador y al alumnado; y cuáles son las fortalezas y debilidades, para potenciarlas o mitigarlas, de las diferentes estructuras académicas y administrativas de la Universidad a cuyo frente se encuentra (BRUNNER, 2011, 145). Para ello, nada mejor que salir de su despacho y visitar los diferentes campus, pero no por la simple voluntad intencionada de aparentar interés por lo que en ellos sucede, en especial cuando se acercan las elecciones, sino para conocer, de primera mano, qué ha pasado, está pasando y puede pasar en las diferentes facultades y departamentos que la integran. No olvidemos que el 
liderazgo se desarrolla diariamente, no en un día; que para gobernar un barco es obligado disponer de un líder que planee su ruta de navegación; y que dicho líder, en este caso el rector o rectora, debe saber fijar prioridades, así como medir el momento oportuno en que es obligado actuar y en qué dirección debe hacerlo (MAXWELL, 2011, $51-52)$.

\section{V.- Equilibrio entre decidir y confiar en el equipo}

Hoy día, nadie duda que hay que saber trabajar en equipo y ser capaz de ilusionar a los mejores en cada área. Lejos del ejercicio soberbio del cargo, presidido por notas autoritarias y jerárquicas, bien haría cualquier rector o rectora en entender que su gestión será mucho más eficiente si la diseña y estructura de modo horizontal (GANGA, 2018, 165), es decir, situándose al frente de la coordinación de un equipo en el que él mismo, tras haberse sabido rodear de los más preparados y motivados, debe ser también capaz de contar con ellos para gobernar, de verdad, la institución.

Ser inteligente en la toma de decisiones es importante, pero tanto o más lo es tomarlas, previo debate con los integrantes de su equipo, habiendo sabido escuchar a la comunidad universitaria, pues ello asegura mayores garantías de acierto y consenso (NOVAK, TERRENCE y MACTAGGART, 2008, 7). Es evidente que el rector o rectora debe tener la suficiente personalidad para tomar medidas. Sin embargo, dicha personalidad, en modo alguno, debe llevarle a tomarlas de forma aislada y por imposición, alejándose de una reflexión necesaria, guiada por la razón y un determinado grado de pragmatismo, en aras a intentar tener mayores posibilidades de acierto y, en paralelo, contar con el respaldo de la comunidad que gobierna (incluso cuando no acierte). La confianza, el respeto y la credibilidad son factores claves en la configuración de un buen líder (LOLAS, 2006, 42).

Tan negativo es un rector o rectora que nunca toma medidas, ya que desde el minuto uno solo está pensando en transitar por el cargo con cierta comodidad y asegurarse la hipotética reelección, como aquel otro que las adopta pensando, erróneamente, que está en posesión absoluta de la verdad y que, en consecuencia, a nadie debe consultar. Quien dirige un equipo debe confiar en él, lo cual también implica su capacidad para delegar y dejar hacer, en el bien entendido que el rector o rectora debe tener la suficiente habilidad como para ser capaz de liderar mediante un ejercicio equilibrado entre la toma de decisiones y la confianza en su propio equipo rectoral (MAXWELL, 2018, 63). 


\section{VI.- Gestión de conflictos}

La toma de decisiones, la acción de gobierno, las características propias del ser humano $\mathrm{y}$, por descontado, los intereses no siempre confluyentes y paralelos que son propios de los diferentes estamentos de la comunidad universitaria, hacen que la gestión del día a día genere ciertos conflictos. Siendo esto así, la máxima autoridad académica a nivel universitario debe ser capaz, de una parte, de anticipar los conflictos, evitando, en la medida de lo posible, que estos surjan o, cuando menos, que lo hagan de forma "controlada"; y de otra, cuando dichos conflictos ya son patentes, de manejar los hilos, combinando justicia y pragmatismo, para alcanzar la solución más ágil y eficaz posible en cada caso concreto (PULIDO, ARTILES Y AGUIAR, 2015, 216).

El rector o rectora, en el plano de la gestión de los conflictos, debe estar motivado y esforzarse en hacer posible lo que, a veces, a primera vista, parece imposible. Y para ello, por ejemplo, nada mejor que inspirar confianza y responsabilidad, a partes iguales, en el cumplimiento de los acuerdos alcanzados. Si se respeta lo acordado será más fácil, sin duda, que la comunidad universitaria vea a su rector o rectora como alguien "de fiar", en quien se puede confiar y que, al mismo tiempo, sabe ejercer su responsabilidad cuando corresponde (GANGA, 2018, 165). Caso contrario, la falta de transparencia en la gestión y la desconfianza hacia su acción de gobierno se convertirán en indeseables “compañeros de viaje" que, más pronto o más tarde, acabarán por pasarle factura y, lo que es peor, jugar en contra del propio prestigio de la institución que dirige.

\section{VII.- Saber comunicar}

Resulta inobjetable que la comunicación constituye una habilidad clave en el ámbito de la alta gestión y política universitaria. En pleno siglo XXI la mala comunicación no es una opción y, además, por si fuera poco, redunda en perjuicio de la reputación de la institución e, incluso, por extensión, en consecuencias negativas a nivel económico para ésta (BERNAL, 2008, 158). Todo rector o rectora debe tener claro que, más allá del fondo de sus mensajes e iniciativas, por interesantes y loables que puedan ser, es obligado saber transmitirlas, dentro y fuera de la propia Universidad, con mensajes claros, comprensibles y en positivo.

Junto a la exigencia de que el rector o rectora sepa comunicar sus mensajes o directrices a los integrantes de su equipo y resto de colaboradores, generando así un flujo de comunicación recíproco que, en última instancia, ha de propiciar un buen ambiente de 
trabajo; así como de aquella otra basada en la transparencia sobre sus acciones de gobierno para con los miembros de la comunidad universitaria (NOVAK, TERRENCE y MACTAGGART, 2008, 10); es evidente que también debiera tener un buen dominio de la oratoria, así como dotarse de un buen gabinete de comunicación no solo orientado a nivel interno, sino también a divulgar los resultados positivos de la docencia, investigación y transferencia que son propios de la institución que dirige (LOLAS, 2006, 39-40). Y todo ello, en un momento como el actual, debe combinarse con un adecuado manejo, a nivel comunicativo, en plena sociedad digital, de las redes sociales y las plataformas informáticas.

Cuando un rector o rectora solo es entrevistado para dar explicaciones, de forma reactiva, sobre situaciones problemáticas que se han convertido en mediáticas, lo hace transmitiendo mensajes negativos para la comunidad universitaria o para la propia institución (PULIDO, ARTILES y AGUIAR, 2015, 216). Si el rector o rectora es visto como un "desconocido social", algo no marcha bien en su gabinete de comunicación.

Las ideas y proyectos son indispensables, pero por sí mismos son insuficientes. La clave de la habilidad comunicativa, junto a la transparencia de la información, consiste en que el liderazgo sea ejercido con una visibilidad mediática equilibrada y en la que la máxima autoridad académica de la Universidad lejos de parecer un insensible y frío comunicador, sea capaz de convencer al receptor, tanto intento como externo, con un discurso convincente, creíble y motivador (O’MULLANE, 2016, 112).

En esta línea, plausible sería que el rector o rectora de una Universidad Pública no fuese un "incapacitado comunicativo", sino, antes al contrario, alguien que estuviese presente en los medios de comunicación con habitualidad, pero sin caer en la trampa de su "sobreexposición", para defender los intereses, con la contundencia que en cada momento sea apropiada, de la institución que dirige y de aquellos colectivos que representa.

\section{VIII.- Innovación equilibrada}

La alta gestión y política universitaria requieren contar con un máximo responsable que sea capaz, junto a su equipo y toda la comunidad universitaria que representa, de anticiparse al futuro, siendo "innovador", cuando proceda, en sus objetivos y decisiones (PULIDO, 2008, 154). En cualquier caso, pensar de forma innovadora debe hacerse 
compatible con la toma de decisiones responsables y reflexivas (RESTREPO y RESTREPO, 2012, 126).

La adopción de medidas conservadoras e inmovilistas en plena época de transformación de la Universidad no es garantía, en todo caso y circunstancia, de éxito. De igual forma, un rector o rectora especialmente "distanciado" de la realidad que debe gestionar, que se dedique siempre a plantear reformas innovadoras, por muy atractivas que puedan resultar, también puede devenir especialmente peligroso, pues muchas veces puede llegar, si no a hacer el ridículo, sí a poner en grave riesgo, con notables hipotecas financieras, a la propia institución que dirige.

De ahí, precisamente, que la máxima autoridad académica de la Universidad deba ser capaz de mantenerse en un cierto equilibrio entre la tradición y la modernidad. Sin llegar a plantear "ideas de bombero" y teniendo presente siempre que los "experimentos mejor es hacerlos con gaseosa", debe ser capaz de asumir, cuando así lo crea conveniente, previa reflexión guiada por la lógica, un cierto riesgo (siempre bien medido) ante la falta aparente de funcionamiento de las alternativas tradicionales. Frente a un rector o rectora, demasiado creativo, así como contra un rector o rectora demasiado lógico, parece mejor optar por un rector o rectora que, junto a su equipo y con el máximo consenso posible de la comunidad universitaria, sepa combinar, en su justa medida, razones creativas y argumentos lógicos en orden a proponer iniciativas y tomar sus decisiones (BERNAL, 2008, 162).

\section{IX.- El valor de la intuición}

La experiencia adquirida, fruto de una gestión de alto nivel previa, es un punto a favor de cualquier rector o rectora que sea elegido para regir el destino de una Universidad. Esta experiencia, siempre que tampoco sea tan elevada y dilatada en el tiempo que pueda repercutir, en paralelo, en una falta de energía y motivación para proponer y hacer cosas, termina, como señalan Novak, Terrence y MacTaggart (2008, 10-11) por favorecer la toma de decisiones más ágiles y guiadas, junto al conocimiento fáctico de la realidad, por una cierta intuición no exenta de pasión.

Si se espera a tenerlo todo atado para tomar una decisión es probable, en ciertos casos, que cuando esa decisión sea tomada ya llegue tarde, esto es, que ya no resulte todo lo efectiva que hubiere sido de haberse adoptado cuando así lo requería la situación. Tan negativa es la toma de decisiones demasiado "maduradas" en que los problemas pueden 
llegar a pudrirse, enquistándose en la institución o en el sentir de uno de los colectivos que la integran; como aquellas otras "demasiado intuitivas" que pueden resultar fruto del "calentón" de un momento en el que no se ha invertido el tiempo suficiente en orden a ponderar sus particulares y colaterales consecuencias (NORTHOUSE, 2015, 92-93). Como así nos dicen las neurociencias, cualquier toma de decisión debiera combinar, en un plazo razonable, que no indebido, el pensamiento social y emocional fruto de la intuición, con una reflexión objetiva, guiada por la lógica (GOLEMAN, 1996, 32). Solo así podrá decirse que la decisión finalmente adoptada lo fue fruto de una adecuada “persuasión racional” (MAXWELL, 2014, 67).

\section{X.- Habilidades de negociación}

Los procesos vinculados con las tres misiones universitarias (docencia, investigación y transferencia e innovación) presididos por una planificación previa, desarrollo y resultados previstos y obtenidos, requieren que los implicados en dichas actividades, en ocasiones representantes de intereses no siempre coincidentes, no se vean como adversarios que deben vencer a quienes están en el otro lado de la mesa de negociación, para así obtener mayores beneficios (CERDÁ y RAMOS, 2011, 409), sino, antes al contrario, como personas unidas en el mismo barco, llamadas a remar en la misma dirección y que, por tanto, tienen por objetivo principal llegar a un acuerdo en el que, sin renunciar a defender los intereses particulares que les sean propios, sean capaces también de aceptar ciertos matices en sus posicionamientos iniciales, alejándose así de “líneas rojas" (PULIDO, 2008, 147-148). Solo de este modo será posible avanzar en la toma de un acuerdo que, en última instancia, sin penalizar a nadie de forma injusta e inmotivada, sea favorable para la Universidad en su conjunto.

Un buen ejemplo sobre este particular, fruto de mi experiencia en el rectorado de la Universitat de Barcelona, bien puede situarse en el Acuerdo alcanzado por el Consell de Govern de la institución, con fecha 27 de enero de 2016, en orden a la aprobación, sin ningún voto en contra, del nuevo mapa departamental de la primera Universidad Pública española en los diferentes rankings internacionales.

Este acuerdo, con todos sus aciertos y también defectos, creo que es un ejemplo paradigmático de cómo alcanzar, en un tema complejo, trufado de notables y comprensibles sensibilidades, un alto consenso en la institución. Consenso que solo fue posible lograr tras haber escuchado las voces de los diferentes centros, así como de los representantes de la comunidad universitaria en el Consejo de Gobierno y Claustro. 
El hecho de que todas y cada una de las Facultades de la Universidad de Barcelona desde su propia reflexión y debate interno, cabe reconocer que no siempre sencillo, fueran capaces, en términos de visión general de los intereses de la institución, de plantear una reorganización de sus departamentos universitarios; que sus líneas esenciales fueran fruto del trabajo participativo de diferentes comisiones y grupos de trabajo claustrales, ciertamente plurales, en los que se contó con la participación de la representación de los sindicatos de profesorado y personal de administración y servicios, así como de la representación, vía Consejo del Alumnado, de las asociaciones de estudiantes; y que nadie en el Consejo de Gobierno y en el propio Consejo Social votase en su contra; bien puede hacer presumir, racionalmente, que las cosas se hicieron, máxime en un momento de intensa crispación social y crisis económica y política, relativamente bien (lo que no quiere decir que no pudieran haberse hecho mejor o que no se cometiesen errores propios de toda acción humana); así como que la Universidad y las personas que la integran siguen estando muy vivas y son capaces, sin ataques externos a su autonomía universitaria, de poner en marcha reformas de hondo calado.

Un trabajo de reorganización departamental derivado de un ejercicio de liderazgo responsable (nada cómodo) que quedó hecho para el siguiente equipo rectoral y que, pese a las voces interesadas que en su día, en plena campaña electoral, se alzaron en su contra, nadie, quizás por comodidad o porque simplemente mintió en el proceso electoral en interés propio, ha sido capaz de reformular o retrotraer a la situación anterior a la reforma o lo, que todavía es peor, de desarrollar e implementar en su totalidad.

\section{XI.- Entusiasmo y espíritu de superación}

Cualquier rector o rectora que pretenda liderar un equipo y, por extensión, la institución de educación superior a cuyo frente se sitúa, debe ser optimista (lo que no implica que desconozca las dificultades del terreno en que se mueve), divertido (lo que no está reñido con la seriedad en su trabajo), ambicioso en su justa medida, pues ello es lo que le facilitará "avanzar" y "superarse", y retador, en la proporción adecuada, en orden a motivar e inspirar a todos los miembros de la comunidad universitaria, así como a involucrarlos, fruto de su propio entusiasmo y convicción, en sus proyectos de gobierno y políticas universitarias (O’MULLANE, 2016, 124-126). 
Un rector o rectora "acomodaticio", triste y poco entusiasta, aun cuando llegase a ser un buen gestor silencioso, lo que no siempre es así, termina por "aburrir" y desincentivar a la comunidad universitaria en cuanto a su real implicación en los desafíos de futuro (también peligros) que "acechan" y afectan a la Universidad Pública. Liderar también es saber motivar, incluso cuando las condiciones del entorno no son las más propicias (GANGA, 2018, 164). Sin ilusión es difícil, por no decir imposible, avanzar. Es obligado detectar oportunidades, crear un ambiente que propicie y estimule respuestas creativas y, por tanto, no cerrarse a nuevos retos (BERNAL, 2008, 157).

\section{XII.- Predicar con el ejemplo}

Como dijo en su día Albert Einstein, si bien el ejemplo no es la mejor manera de enseñar, no es menos cierto que sí es la única. Si un rector quiere "enseñar" el camino a su equipo y al resto de la comunidad universitaria, tiene que ser el primero en "dar ejemplo", esto es, en trabajar, asumir las consecuencias de la toma de decisiones que implica su cargo (aunque, a veces, en el corto plazo, es posible que no sean las más populares), y hacerlo con honestidad.

No parece un buen modelo a seguir el de un rector o rectora que, mientras mediante su vicerrectorado de economía y gerencia "recuerda", a diario, a los representantes de los diferentes colectivos universitarios y al Estado y Comunidad Autónoma, que la situación económica de su Universidad es "asfixiante", hasta el extremo de que le es casi imposible "levantar la persiana", adopta, en paralelo, como una de sus primeras medidas de gobierno, el incremento del sueldo de su gerente en un $10 \%$. Ello es así, porque, si la máxima autoridad de una Universidad se ve obligada a reclamar “comprensión y sacrificios" a su personal, así como a reivindicar, lo cual es justo y necesario, una financiación pública, suficiente y estable de su institución, resulta absolutamente contradictorio (sin perjuicio que tampoco es nada ético) que, al mismo tiempo, dilapidando fondos públicos, opte por un incremento de sueldo, desmesurado, de aquél, su gerente, que, para más inri, es quien debe comunicar a los empleados que "no hay dinero para nada" y negociar con los gobiernos respectivos la mejora de la financiación de la propia Universidad (MARIANOV y VON, 2006, 138). 


\section{XIII.- Los diferentes estilos de liderazgo y su aplicación en el ámbito de la Universidad Pública}

A grandes rasgos es posible individualizar seis grandes estilos de liderazgo: el commanding o mando, el visionary o visionario, el affiliative o empático, el democratic o demócrata, el pacesetting y el coaching (GOLEMAN, MCKEE, y BOYATZIS, 2003, 32). Un buen líder universitario debiera no ceñirse a uno solo de dichos estilos o métodos, así como mostrar su capacidad para adaptarse a las particularidades de cada uno de ellos en atención a la realidad y circunstancias que son propias de cada momento histórico, político, económico, educativo y social (NORTHOUSE, 2015, 86).

El estilo commanding o de mando, que bien podría resumirse en la expresión "haz lo que yo mande", no parece el más apropiado para ser seguido, en su día a día, por el más alto cargo académico de una Universidad. Sin embargo, en tiempos de crisis o en el momento de dar un golpe de timón en la dirección, gestión y organización de la institución, de forma muy limitada y excepcional en cuanto a su aplicación, puede resultar útil, cuando no imprescindible, para luchar con no pocos "inmovilismos internos" que son propios de la Universidad (O’MULLANE, 2016, 97-101).

Todo rector o rectora debiera guiarse más bien, en su día a día, generando motivación y entusiasmo, por ejercer un estilo de liderazgo visionary, de tal forma que sea capaz de movilizar los intereses, no pocas veces contrapuestos de los diferentes estamentos universitarios, en aras a alcanzar un bien superior común (NORTHOUSE, 2015, 92-96). Este estilo de liderazgo, resumido en la máxima "ven conmigo", útil en tiempos de cambio que requieren una visión clara y motivadora del futuro, solo funciona cuando el rector o rectora conoce bien la realidad a la que se enfrenta en su gestión (LOLAS, 2006, 44).

Este estilo "visionario" que se acaba de describir, en cualquier caso, debe compatibilizarse, desde la gestión de equipos, con aquel otro que responde al modelo affiliative, en el que el rector o rectora, bajo la máxima de que "las personas son lo primero", debe ser capaz de generar armonía y vínculos emocionales entre los miembros de su equipo rectoral y, por extensión, con la comunidad universitaria. Con todo, este estilo de liderazgo empático, útil en cuanto motivacional, no parece que deba ser exagerado irracionalmente, pues llevado al extremo puede terminar por derivar, en no pocos casos, en una manifiesta falta de dirección y en un "dejarse llevar" que puede ser cómodo, pero no siempre eficaz. 
De igual forma, todo rector o rectora también debe ejercer su liderazgo con seguimiento de un modelo democrático. La mejor forma de alcanzar el consenso tiene que ver con la participación activa de todos los interesados y afectados por las decisiones que puedan adoptarse en el ámbito de la Universidad. Resulta especialmente conveniente, por no decir obligatorio, que la máxima autoridad académica universitaria siempre pregunte a la comunidad universitaria ¿qué piensa?

De este modo, no solo estará bien informado, sino que, además, generará un clima más apropiado en orden a la generación de la aceptación respecto a las políticas que desee implementar (NORTHOUSE, 2015, 101). Con todo, no convendría confundir, especialmente en el ámbito universitario, presidido por ciertos "reinos de taifas", la lucha decidida y consciente por la obtención del "máximo consenso posible" sobre un tema, con la "unanimidad de opinión" sobre éste (O’MULLANE, 2016, 110-111). Ello es así, porque buscando la unanimidad, ciertamente compleja (a veces imposible por los intereses contrapuestos en juego a los que afectará una decisión específica) no solo se corre el riesgo de "perder el tiempo" y, por extensión, las "oportunidades", sino también de no llegar nunca a tomar ninguna decisión trascendente y necesaria para el presente y futuro de la Universidad.

Desde otra perspectiva de acción, relacionada directamente con la gestión de su propio equipo de dirección, el rector o rectora bien haría en aplicar, en ciertos casos, el estilo de un liderazgo pacesseting. La utilización de dicho método, fundado en la máxima "haz lo que hago, ahora", es una alternativa interesante en aras a gozar de un equipo cohesionado, motivado, competente y que sea capaz de alcanzar un rendimiento alto en el ejercicio responsable de sus respectivas competencias (GOLEMAN, MCKEE, y BOYATZIS, 2003, 47-49). Llevado al extremo dicho estilo puede derivar en una desmotivación interna (O’MULLANE, 2016, 103-105), en tanto que los vicerrectorados no pasen de ser "peones acríticos" movidos por el rector o rectora; pero, bien aplicado, puede terminar por generar complicidades personales y profesionales entre la máxima autoridad académica y los miembros de su equipo, lo cual puede generar, en positivo, que los integrantes del equipo de dirección "hablen y se involucren mucho más" (en especial, cuando se les respeta y, en muestra de confianza, se les concede un amplio grado de autonomía en orden a la toma de decisiones en su ámbito competencial de gestión). 
Señalar, por último, que, junto a los anteriores modelos de liderazgo universitario que se acaban de exponer, resulta también obligado traer a colación el modelo coaching, utilizado con el objetivo de mejorar, cara al futuro, la eficiencia de los integrantes del equipo rectoral. Bajo la fórmula gráfica del "prueba esto", a modo de consejo a ponderar, este estilo bien puede repercutir en la mejora de rendimiento de las diferentes áreas competenciales en armonía con la política del rectorado, así como reforzar las fortalezas presentes y futuras de los integrantes del equipo de dirección (y resto de funcionarios y trabajadores).

Como decía al principio de este apartado, todo rector o rectora debiera conocer, en primer lugar, cuáles sean los diferentes modelos en que puede ejercer su liderazgo (RESTREPO y RESTREPO, 2012, 126-127). Solo así, conociendo sus virtudes y defectos, así como siendo consciente de lo que puede o debe hacer, será posible contar con una máxima autoridad académica que, ante circunstancias cambiantes y personalidades muy heterogéneas, sea capaz, en última instancia, de jugar con los diferentes estilo de liderazgo no solo combinándolos, sino también sabiendo cuál pueda ser en cada caso concreto, dadas las circunstancias del momento, el más efectivo para tomar decisiones racionales, eficaces y positivas para la institución que dirige.

\section{XIV.- Notas conclusivas sobre las habilidades en la alta gestión y la política universitaria}

De todo cuanto antecede cabe deducir que todo rector o rectora tiene suficiente información acerca de lo que está bien o no en materia de liderazgo de la institución universitaria. Con todo, alejándonos de los falsos mitos, parece conveniente fijar una serie de notas conclusivas sobre las habilidades en la alta gestión y la política universitaria (en especial, por lo que hace referencia a la figura del rector o rectora):

Primera.- Todo rector o rectora tiene la obligación de convertirse en un verdadero líder, pues está llamado a impulsar el mejor desarrollo de su equipo de dirección y personal de administración técnico, así como a ser capaz de motivar e involucrar a la comunidad universitaria en la consecución de objetivos comunes en beneficio de la institución que dirige y representa.

Segunda.- Es evidente que para ser un buen líder hay que tener una habilidad innata. Sin embargo, mucho más trascendente que tener esa habilidad (que también puede y debe trabajarse y perfeccionarse) es saber colocarla al servicio de la construcción de un 
liderazgo ejemplar. Para ser líder es bueno "nacer líder", pero con ello no basta. Hay que trabajar dicha habilidad con sentido común y al servicio del buen funcionamiento del equipo rectoral y de la obtención de las metas y objetivos fundamentales consagrados en el programa de acción rectoral.

Tercera.- Los rectores y rectoras no siempre tienen las respuestas correctas ante cada problema que se les plantea, pero sí son capaces de hacerse las preguntas correctas en cada caso y momento concreto, saben a quién deben formularle dichas preguntas, ostentan la cualidad de saber escuchar activamente, asumen responsabilidades y, por último, son capaces, con aciertos y errores, propios de la falibilidad humana, de tomar, cuando toca, dichas decisiones con el máximo consenso (que no tiene por qué implicar unanimidad de aceptación por la comunidad universitaria).

Cuarta.- Todo rector o rectora debe tener una cierta dosis de ambición, pero en el bien entendido que las acciones a aplicar, en cada caso concreto, no deben tomarse en interés particular (o incluso del que es propio de un colectivo de la comunidad universitaria), sino, antes al contrario, en beneficio de la Universidad y de todos y cada uno de los integrantes de sus diferentes estamentos.

Quinta.- Cualquier persona puede llegar a liderar si así lo desea, pues la voluntad es un factor clave para ello. Sin embargo, la voluntad de ser líder, aun siendo importante, no configura, por sí misma, un buen liderazgo. Hace falta mucho más y, en especial, que quien asuma el papel de rector o rectora de una Universidad Pública tenga muy claro qué quiere hacer, qué puede hacer, cómo puede hacerlo, qué consensos debe tejer para conseguirlo, qué precio (incluso electoral cara una hipotética reelección) está dispuesto a pagar, qué sacrificios personales y familiares debe enfrentar para ejercer su cargo, cuál sea su voluntad de servicio a la comunidad, que la comodidad no es compatible con la toma de decisiones propia de su cargo y, por último, que por mucho rector o rectora que sea, no deja ser un miembro más de la comunidad universitaria, como cualquier otro, de tal forma que lejos de "endiosarse" y "encerrarse" en sí mismo (rodeado de los "palmeros" de turno) recuerde, en todo momento, que su opinión no es la "verdad absoluta" y que "entre todas y todos" es mucho más fácil acertar con las recetas que requiere la Universidad o, cuando menos, equivocarse menos en cuanto a su individualización e implementación.

El desafío está servido y no es fácil ni cómodo. Quien quiera ser rector o rectora debe enfrentar su decisión con valentía, ejerciendo un liderazgo no exento de cierta audacia, 
pero no temerario. Y quien ya es rector o rectora y no lo está asumiendo, bien haría en dimitir o cambiar su forma de actuación, pues no hacerlo no solo le convierte en una "alma en pena", sino que, por extensión, penaliza a la institución que está llamado a dirigir.

\section{Bibliografía referenciada}

ANDRÉS AUCEJO, E. (2017). La evaluación de la actividad investigadora en ciencias jurídicas: hacia un impacto nacional y un impacto internacional en las ciencias jurídicas. Revista Educación y Derecho 16, 1-25.

BERNAL AGUDO, J. L. (2008). Competencias de liderazgo. En: J. Gairín y S. Antúnez (Co.) Organizaciones educativas al servicio de la sociedad. Barcelona: Wolters Kluwer (pp. 155-162).

BRUNNER, J. (2011). Gobernanza universitaria: tipología, dinámicas y tendencias. Revista Educación 355, 137-159.

CABEZAS HOLGADO, E., AIGER VALlÉS, M. y PALACÍN LOIS, M. (2017). Implicaciones de la realizatividad pragmática en la construcción del liderazgo. Círculo de lingüística aplicada a la comunicación 71, 141-158.

DI NAPOLI, R. (2009). Academic identities and team management: mission impossible? REDU:Revista de Docencia Universitaria 4, 1-13.

GANGA CONTRERAS, F. et. al. (2018). Relevancia del liderazgo en el gobierno de las universidades iberoamericanas. Interciencia: Revista de ciencia y tecnología de América 43 (3), 160-167.

GOLEMAN, D., MCKEE, A. y BOYATZIS, R. (2003). El líder resonante crea más. Madrid: Nuevas Ediciones de Bolsillo.

GOLEMAN, D. (1996). Inteligencia emocional. Barcelona: Kairós.

LOLAS STEPKE, F. (2006). Sobre modelos de gestión universitaria. Calidad en la educación (ejemplar dedicado a la gestión de las instituciones de educación superior) $24,37-45$.

MARIANOV, V. y VON CHRISMAR, M. (2006). La gobernabilidad de las instituciones de educación superior y el lugar de la participación. Calidad en la 
educación (ejemplar dedicado a la gestión de las instituciones de educación superior) $24,133-145$.

MARTÍNEZ, R. (2012). Reflexions entorn el sistema de govern de les Universitats davant el repte de la modernització de la governança universitària. Revista catalana de dret públic (monogràfic sobre Canvi de model a la Universitat?) 44, 110-154.

MAXWELL, J. C. (2018). La Biblia del liderazgo de Maxwell. New York: Harper Collins.

MAXWELL, J. C (2014). Buenos líderes hacen buenas propuestas. Londres: Routlege.

MAXWELL, J. C. (2011). Las 21 leyes irrefutables del liderazgo. Siga estas leyes y la gente le seguirá a usted. Madrid: Nelson Editorial.

MIRÓN, A. (2008). La problemática de la gestión universitaria: los retos y la incapacidad para resolverlos. Revista Iberoamericana de Educación, 48 (1), 1-11.

MURILLO GARCÍA, F. y SALAS DURAZO, I. A. (2011). Gestión universitaria y estilos de liderazgo. Cuadernos de Educación y Desarrollo 30, 1-9.

NORTHOUSE, P. G (2015). Leadership: Theory and practice. London: Sage Publications.

NOVAK, R., TERRENCE J. y MACTAGGART, L. (2008). Higher education governance in the United States. La Cuestión Universitaria 3 (ejemplar dedicado a Las innovaciones en la organización y el gobierno de las universidades), 6-12.

O’MULLANE, M. (2016). University Leadership: approaches, formation and challenges in Europe. Hampshire: Palgrave Macmillan.

PONS RAFOLS, F. (2013). La función social de la universidad y la presencia de actores externos en sus órganos de gobierno. Revista Educación y Derecho 7, 1-20.

RESTREPO, J. M. y RESTREPO TORRES, M. (2012). Cinco desafíos en el ejercicio del liderazgo en los rectores de colegios. Educación y educadores 15 (1), 117-129.

RODRÍGUEZ PULIDO, J. (2008). Competencias organizativas para el desarrollo de la función directiva. En: J. Gairín y S. Antúnez (Co.) Organizaciones educativas al servicio de la sociedad. Barcelona: Wolters Kluwer (pp. 143-154). 
RODRÍGUEZ PULIDO, J., AGUIAR PERERA, M. A. y ARTILES RODRÍGUEZ, J. (2016). Formación de gestores universitarios en Argentina, Chile, Ecuador, Perú, Uruguay y Venezuela. Revista Calidad en la Educación Superior 7 (1), 284-300.

RODRÍGUEZ PULIDO, J., ARTILES RODRÍGUEZ, J. y AGUIAR PERERA, M. A. (2015). La gestión universitaria: dificultades en el desempeño del cargo y necesidades de formación. REDU: Revista de Docencia Universitaria 13 (3), 213-231.

ROSOVSKY, H. (2010). La Universidad. Historia y futuro de la Universidad de Palermo. Revista Argentina de Educación Superior 2, 166-174.

SAN JUAN FERNÁNDEZ, M. y BUENO VILLAVERDE, A. (2017). Estilos de liderazgo en la gestión académica universitaria española. En: J. Murillo (Co.) Avances en liderazgo y mejora de la educación: Actas del I Congreso Internacional de Liderazgo y Mejora de la Educación. Madrid: RILME (pp. 256-259).

VALLESPÍN PÉREZ, D. (2019). La apuesta por un modelo colegial de universidad con participación de partes interesadas. Universidad-Sí: Blog de Studia XXI, 1-3.

VALLESPÍN PÉREZ, D. (2013). La gobernanza de la Universidad: el camino hacia un "cambio razonable" compatible con el respeto a la autonomía universitaria. Revista Educación y Derecho 7, 1-8. 